None. P. Lohneis: None. A. Lechner: None. S. Wagener-Ryczek: None. P.S. Plum: None. D. Pfister: None. F. Dörr: None. D. Beutner: None. F. Thangarajah: None. D. Ratiu: None. W. Malter: None. S. Merkelbach-Bruse: None. C.J. Bruns: None. A. Quaas: None. M.S. von Bergwelt-Baildon: B. Research Grant (principal investigator, collaborator or consultant and pending grants as well as grants already received); Significant; Astellas. F. Consultant/Advisory Board; Modest; Bristol-Myers Squibb. H.A. Schlößer: B. Research Grant (principal investigator, collaborator or consultant and pending grants as well as grants already received); Significant; Astra Zeneca.

\section{P03.16 FUNCTIONAL DEFECTS IN B-CELLS OF PATIENTS WITH VON-HIPPEL-LINDAU SYNDROME}

${ }^{1} \mathrm{~S}$ Theurich*, ${ }^{2} \mathrm{HJ}$ Becker, ${ }^{3} \mathrm{~K}$ Wennhold, ${ }^{3} \mathrm{H}$ Schlösser, ${ }^{3} \mathrm{~F}$ Marbach, ${ }^{3} \mathrm{M}$ Garcia-Marquez, ${ }^{3} \mathrm{~A}$ Shimabukuro-Vornhagen, ${ }^{3} \mathrm{~J}$ Schreml, ${ }^{1} \mathrm{M}$ von Bergwelt-Baildon. 'LMU Munich, Munich, Germany; ' University of Tokio, Tokio, Japan; ${ }^{3}$ University Hospital Cologne, Cologne, Germany

\subsection{6/jitc-2020-ITOC7.55}

Von-Hippel-Lindau (VHL)-disease is an inherited cancer syndrome characterized by a variety of benign and malignant tumors, which develop upon mutation of the second allele of the VHL-tumor suppressor gene. The VHL-protein (pVHL) regulates hypoxia-induced transcription factors (Hif) and by this plays a central role for metabolic cellular adaptations to hypoxic conditions. VHL/Hif regulation plays a well-established role in the development and function of immune cells and already VHL-haploinsufficiency can alter gene expression patterns. In contrast, little is known about primary immune cell functions in VHL-patients. In this study, we analyzed the functional capacity of CD40-stimulated B-cells to act as antigen-presenting cells. We confirmed mono-allelic VHL-gene mutations in B-cells from thirteen VHL-patients and found that their response to CD40-stimulation was significantly reduced. On a functional level this translated to an impaired ability to act as antigen presenting cells leading to impaired Tcell responses in vitro. Taken together, we demonstrate that VHL-haploinsufficiency deregulates B-cell functions following CD40-activation as a new aspect of VHL-syndrome. (The study was registered in the German Clinical Trial Registry (www.drks.de); ID: DRKS00012413).

Disclosure Information S. Theurich: B. Research Grant (principal investigator, collaborator or consultant and pending grants as well as grants already received); Modest; Verein VHL (von Hippel-Lindau) betroffener Familien e.V.. H.J. Becker: None. K. Wennhold: None. H. Schlösser: None. F. Marbach: None. M. Garcia-Marquez: None. A. Shimabukuro-Vornhagen: None. J. Schreml: None. M. von Bergwelt-Baildon: None.

\section{P03.17 UPA-PAI-1 HETEROMERS PROMOTE ADVANCED STAGES OF BREAST CANCER BY ATTRACTING PRO-TUMORIGENIC NEUTROPHILS}

${ }^{1} \mathrm{~B}$ Uhl ${ }^{*},{ }^{1} \mathrm{~L}$ Mittmann, ${ }^{1} \mathrm{~J}$ Dominik, ${ }^{1} \mathrm{~J}$ Schaubächer, ${ }^{1} \mathrm{C}$ Braun, ${ }^{1} \mathrm{R}$ Pick, ${ }^{1} \mathrm{M}$ Canis, ${ }^{2} \mathrm{~S}$ Kanse, ${ }^{3} \mathrm{~W}$ Weichert, ${ }^{1} \mathrm{M}$ Sperandio, ${ }^{1} \mathrm{~K}$ Lauber, ${ }^{1} \mathrm{~F}$ Krombach, ${ }^{1} \mathrm{CA}$ Reichel. ${ }^{1}$ University Hospital, Ludwig-Maximilians-University (LMU) Munich, München, Germany; ${ }^{2}$ University of Oslo, Oslo, Norway; ${ }^{3}$ Technical University of Munich, München, Germany

10.1136/jitc-2020-ITOC7.56
Background High tumor levels of urokinase-type plasminogen activator (uPA)-plasminogen activator inhibitor-1 (PAI-1) heteromers independently predict poor survival in early breast cancer. The pathogenetic role of this protein complex, however, remains largely obscure.

Materials and Methods Neutrophil trafficking was analyzed in orthotopic (multi-channel flow cytometry) and heterotopic (ear; multi-channel in vivo microscopy) mouse models of 4T1 breast cancer, in a mouse peritonitis assay (multi-channel flow cytometry), as well as in the mouse cremaster muscle (multi-channel in vivo microscopy). Cytokine expression in tumors was determined by multiplex ELISA. Phenotypic and functional properties of primary mouse neutrophils, microvascular endothelial cells (cell line bEnd.3), macrophages (cell line RAW 264.7), and breast cancer cells (cell line 4T1) were characterized in different in vitro assays. uPA/PAI-1 expression and neutrophil infiltration in human breast cancer samples were assessed by RNA sequencing, immunhistochemistry, and ELISA.

Results Here, we demonstrate that uPA-PAI-1 heteromerization multiplies the potential of the single proteins to attract protumorigenic neutrophils. To this end, tumor-released uPA-PAI1 utilizes very low density lipoprotein receptor and ERK mitogen-activated protein kinases to initiate a pro-inflammatory program in peritumoral macrophages. This promotes neutrophil trafficking to cancerous lesions and primes these immune cells towards a pro-tumorigenic phenotype, thus supporting tumor growth and metastasis. Blockade of uPA-PAI-1 heteromerization by a novel inhibitor effectively interfered with these events and prevented tumor progression.

Conclusions Our findings identify an already therapeutically targetable interplay between hemostasis and innate immunity that drives advanced stages of breast cancer. As a personalized immunotherapeutic strategy, blockade of uPA-PAI-1 heteromerization might be particularly beneficial for patients with highly aggressive uPA-PAI- $1^{\text {high }}$ tumors.

This study was supported by Deutsche Forschungsgemeinschaft (DFG), Sonderforschungsbereich (SFB) 914.

Disclosure Information B. Uhl: None. L. Mittmann: None. J. Dominik: None. J. Schaubächer: None. C. Braun: None. R. Pick: None. M. Canis: None. S. Kanse: None. W. Weichert: None. M. Sperandio: None. K. Lauber: None. F. Krombach: None. C.A. Reichel: None.

\section{P03.18 ABSTRACT WITHDRAWN}

\section{P03.19 EVALUATION OF IMMUNOGENICITY DIFFERENCES IN LLC1 AND GL261 TUMOR MODELS FOR EFFECTIVE CHEMO-IMMUNOTHERAPY TREATMENT}

K Zilionyte*, A Mlynska, V Pasukoniene. National Cancer Institute, Vilnius, Lithuania

\subsection{6/jitc-2020-ITOC7.57}

Background Tumor immunogenicity is a critical factor responsible for the limited success of cancer immunotherapy and determine the need for personalized treatment. Correct evaluation of effectiveness of cancer treatments and their combination is inseparable from the proper selection of the experimental tumor model. The lack of knowledge about the immunogenicity of animal tumor models makes it difficult to evaluate the efficacy of cancer immunotherapy and becomes 